\title{
Using non-destructive test to validate and calibrate smart sensors for urban pavement monitoring
}

\author{
A. Di Graziano, S. Cafiso \& A. Severino \\ Department of Civil and Architectural Engineering, University of Catania, Italy \\ F. Praticò, R. Fedele \& G. Pellicano \\ Department of Information Engineering, Infrastructure and Sustainable Energy, University Mediterranean \\ of Reggio Calabria, Italy
}

\begin{abstract}
In the context of smart cities, infrastructures play a strategic role to guarantee sustainability, efficiency, safety, and resiliency. Several solutions can be adopted, but the key factor for the success of the solution selected is its ability of improving the maintenance management process.

Specifically, in order to timely identify pavement needs, early, effective and continuous monitoring is needed to reduce total costs and to extend service life. Over the years several efforts have been made to implement more advanced and effective monitoring systems at ever more contained costs, going from impractical manual and destructive methods through automated in vehicle equipment to the most recent Smart Sensor Network (SSN) embedded into/ positioned on the pavement. While traditional systems (GPR and FWD) are currently used in road pavement maintenance where they have shown their reliability and effectiveness, instead smart sensors in pavement maintenance are promising but in the early stage of investigation.

The objective of the presented study is to test a solution that can be used to make smarter the road pavement monitoring. Specifically, this paper details an urban site investigation comprising Ground Penetrating Radar (GPR), Falling Weight Deflectometer (FWD) and vibroacoustic sensors. GPR and FWD are used for providing reference data of pavement bearing capacity. In the paper, tests and results in selected trial sites are used to identify Strengths, Weaknesses, Opportunities, and Threats (SWOT analysis) of the application of smart vibroacoustic sensors for the assessment of pavement residual life.

Results show that the method is able to evaluate pavement deterioration (above all in terms of presence and entity of cracks) by means of meaningful features extracted from the vibroacoustic signatures (acoustic signals) of the road pavement loaded by urban traffic, with the aim of using these data to build innovative performance curves able to improve an urban pavement management system.
\end{abstract}

Keywords: In-situ measurements, NTD, smart sensors, pavement condition

\section{INTRODUCTION}

The success of the smart city is strictly related to the ability of transportation infrastructures to guarantee sustainability, efficiency, safety, resiliency, and improve the maintenance management (Praticò, 2001). Specifically, in order to timely identify pavement needs, early, 
effective, and continuous monitoring is needed, aiming at reducing total costs and at extending service life (Odoki et al., 2015).

Traditional approaches, such as the analysis of pavement samples (cores/slabs), Ground Penetrating Radar (GPR), Falling Weight Deflectometer (FWD), Light Weight Deflectometer (LWD), are currently used in road pavement maintenance. Their reliability and effectiveness is well-known, as well as their potential weaknesses, such as (i) providing punctual measure (lack of effectiveness), (ii) being based on expensive devices or destructive tests (lack of sustainability), (iii) partly or completely implying the closure of the road section (which negatively affects the vehicular traffic and road safety, lack of safety), (iv) using traditional data management (lack of intelligence), and (v) being based on stand-alone devices (lack of connectivity).

Over the years, several efforts have been done to implement more advanced (i.e., effective, intelligent, safe) monitoring systems at lower costs (i.e., sustainable). Several monitoring solutions were proposed from impractical manual and destructive methods, through automated in-vehicle equipment, to the recent Smart Sensor Networks (SSN) embedded or positioned on the pavement (Di Graziano et al. 2020). In more detail, the following classes of solutions were identified together with their advantages and disadvantages:

1) Embedded sensor-based systems (Advantages: Do not affect the drivers' safety; Allow detecting internal conditions of a road section with great accuracy. Disadvantages: Need to be installed during construction or damage the road surface if installed on an existing road. Short life time due to harsh operation conditions. (Zhou et al., 2012; Hasni et al., 2017)).

2) Non-embedded sensor-based systems (Advantages: Non-destructive. Disadvantages: Often allow measuring surface conditions, or deriving internal condition based on surface measurements. (Praticò et al., 2017; Iodice et al., 2020).

3) Mobile systems (Advantages: Do not need installation on site; Able to scan wide road surfaces/sections. Do not interfere with the traffic. Disadvantages: Usually based on expensive devices. Require high computational effort (especially if they use images/videos as input data). Provide results that represent the average condition of a road surface/section (Yi et al., 2015; Cafiso et al., 2019).

4) Stationary systems (Advantages: Provide results (often) more accurate than the ones of mobile systems. Often interfere with the traffic. Disadvantages: Provide results that represent the condition of a point of a road surface/section (Grace, 2015; Fernandes and Pais, 2017).

5) Wireless systems (Advantages: Do not need wire for their connection (energy- and data transmission-related). Allow covering large areas (e.g., using Wireless Sensor Network). Disadvantages: May need widespread system of antennas or satellites. Need fast and secure protocols for data transmission. (Ceylan et al., 2013; Merenda et al., 2020).

6) Wired systems (Advantages: Do not affected by power and connection outages. Disadvantages: Often destructive. Do not allow long distance data transmission. (Yu et al., 2013; Iuele et al., 2019);

7) Self-powered systems (Advantages: Do not need energy sources. Disadvantages: Are in an early stage of development. Allow short time monitoring. Often have low autonomy. (Hasni et al., 2017; Fedele et al., 2018).

8) Traditional data management (Advantages: Based on well-known techniques such as sampling, filtering, and analyzing. Disadvantages: Do not allow automatic extraction of information from the recorded data. (Mounier et al., 2012; Ouma and Hahn, 2017).

9) Smart data management (Advantages: Allow the extraction of meaningful information from the recorded data using machine learning, big data, and artificial intelligence. Allow safe and prompt data transmission/exchange (among things, and between things and users). Disadvantages: Often need big data and interdisciplinary knowledge. Require high computational effort (Ceylan et al., 2014; Praticò et al., 2020).

Despite the advantages promised by the innovative solutions described above, it is really difficult to find applications in real contexts, and often they are in the early stage of investigation. 
Based on the above, the main objective of the presented study is to test a solution that can be used to make smarter the road pavement monitoring. In more detail, an urban site investigation was carried out using as source of noise and vibration a FWD and a LWD, and an innovative vibro-acoustic sensor as receiver of the response of the road pavement to wellknown loads produced by the sources cited above.

The characterization of the different road sections investigated (damaged and un-damaged) was carried out through a GPR and a FWD, which were used for providing reference data of pavement bearing capacity.

In the paper, tests and results in selected trial sites are used to identify Strengths, Weaknesses, Opportunities, and Threats (SWOT analysis) of the application of smart vibroacoustic sensors for the assessment of pavement residual life.

Consequently, the remaining part of the paper is organized as follows. Section 2 aims at describing the equipment used in this study to characterize the road sections under investigation. Section 3 aims at presenting the innovative vibro-acoustic sensor proposed in this study. The road trial is included in Section 4, which is followed by Section 5 that presents the main results of the study. Finally, conclusions and future works are followed by the references.

\section{MONITORING EQUIPMENTS}

\subsection{Ground Penetrating Radar (GPR)}

The ground penetrating radar is a geophysical radar system with two antennas and receivers used to perform non-destructive investigations of underground characteristics with high resolution and in depth (up to $3.2 \mathrm{~m}$ from the surface).

GPR operation principle is based on electromagnetic theory, its functioning consists in sending short electromagnetic pulses into a medium and when pulses achieve an interface they are reflected back partially and collected by the receiving antenna (Figure 1). The reflected energy is displayed in wave-forms and the greatest amplitudes represent the interfaces between layers with distinct dielectric characteristics (Daniels, 2004). Therefore, GPR measures the travel time between the transmission of the energy pulses and its reception. Transmission and reception of radar pulses are performed from one or more antennas that are moved on the investigated medium. The collected data are processed and saved on a control unit, that is also used to generate the necessary pulses for the operation of the antennas.

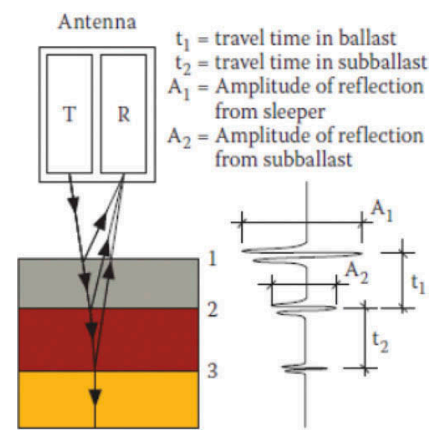

Figure 1. GPR principles (Saarenketo, 2006).

As mentioned GPR can provide a fast, nondestructive measurement technique for evaluating asphalt layer, presence of infrastructural interferences within the pavement, or to assess infrastructural conditions (Goulias et al., 2020). 
Thickness of the asphalt layer can be calculated by two methods: two-way travel time or the common midpoint method (Lahouar et al., 2002) when multiple GPR channels are available. Since urban pavement present thin layers, it is often challenging to differentiate the reflection from the top and bottom of the layer. Antennas with a center frequency of $2000 \mathrm{MHz}$ can provide a sufficient resolution to measure a minimum layer thickness less than $2.5 \mathrm{~cm}(1 \mathrm{in}$.) with an accuracy of $0.25 \mathrm{~cm}$ (0.1 in.) (ASTM D4748). Moreover, when GPR approaches above a pipe, a cable duct or a manhole, the two-way travel time versus travel distance has a parabolic shape (Al-Qadi et.al., 2005), so it is possible to highlight the presence of these types of interferences. The GPR used in the present study uses two antennas with $600 \mathrm{MHz}$ and $2000 \mathrm{MHz}$ frequencies. The K2_FW acquisition software is used to manage the phases of radar acquisition and to review the data acquired directly on site. The default field propagation speed is equal to $10 \mathrm{~cm} / \mathrm{ns}$.

\subsection{Falling Weight Deflectometer (FWD)}

The FWD is a non-destructive field test which is designed to simulate deflection of a pavement surface caused by a fast-moving truck. The device simulates the load conditions of a heavy vehicle and estimates the pavement's response by measuring the basin of deflection using several sensors fixed on a beam. The conventional FWD is able to apply loads in the range of 7-140 kN, even if the standard load used for structural pavement analysis is usually $30-50 \mathrm{kN}$ producing about $700 \mathrm{kPa}$ pressure under the load plate. The device allows a variable weight to be dropped from a variable height and the load is applied to the superstructure through a circular loading plate and weights from 50 to $400 \mathrm{Kg}$. The generated duration of the half sine pulse is typically $30 \mathrm{~ms}$, corresponding to the loading time produced by a truck moving at $40 \mathrm{Km} / \mathrm{h}$. The FWD used in the present study (Figure 2 ) is equipped with a loading plate of $300 \mathrm{~mm}$ diameter, 9 geophones positioned in the direction of the road, a load of $250 \mathrm{~kg}$ and 4 standard heights (50-100-200-390 mm) able to produce a stress of 500-1700 $\mathrm{kPa}$ (Cafiso and Di Graziano, 2009).

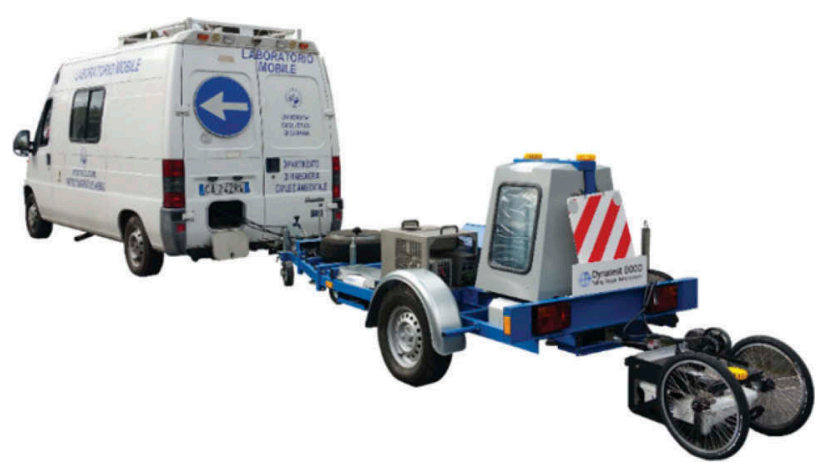

Figure 2. Falling Weight Deflectometer.

\section{VIBRO-ACOUSTIC SENSORS}

Based on the analysis reported in section 1, an innovative monitoring system was designed and several studies were carried out to set up and improve both the system and the data analysis method (see, e.g., (Fedele and Praticò, 2019; Fedele, 2020; Merenda et al., 2020; Praticò et al., 2020).

In more detail, the proposed solution consists of a system and a method (Figure 3 ) that aim at monitoring the Structural Health Status (SHS) of road pavements, designed bearing in mind concepts such as innovation, sustainability, efficiency, and intelligence. The solution is 
based on sensors that are attached on the road surface, i.e., it is a non-destructive test (NDT)based solution. The solution is innovative because of the fact that it refers to the concept of vibro-acoustic signature. i.e., the vibro-acoustic response of pavement to loads. In more detail: 1) The vibrations are produced by the vehicles (source) that propagate into the road layers. 2) The corresponding variation of air pressure is detected by a microphone placed inside a sound insulating coating.

More precisely, the acoustic receiver consists of sound isolated microphone + external sound card + laptop for recording, processing and analyzing the received data (Figure 3 ). Importantly: 1) The road pavement is considered as an acoustic filter with a given SHS. 2) The method aims at detecting hidden cracks into the road section (e.g., under the wheel paths), while they are damaging the "acoustic filter" and before they arrive to the road surface. 3) The worsening of the SHS of the road pavement (filter) is recognized using the variation of meaningful features extracted from the recorded signals (vibro-acoustic signatures of the monitored pavement), in such a way as to obtain an efficient and intelligent solution.

Note that the receiver shown in Figure 3 (used in this study) is one of the possible systems that can be used to the purposes mentioned above, and that it is being improved (seeking to obtain a self-powered wireless system) in order to address some of the objectives of the ongoing Italian project USR342-PRIN 2017-2022.

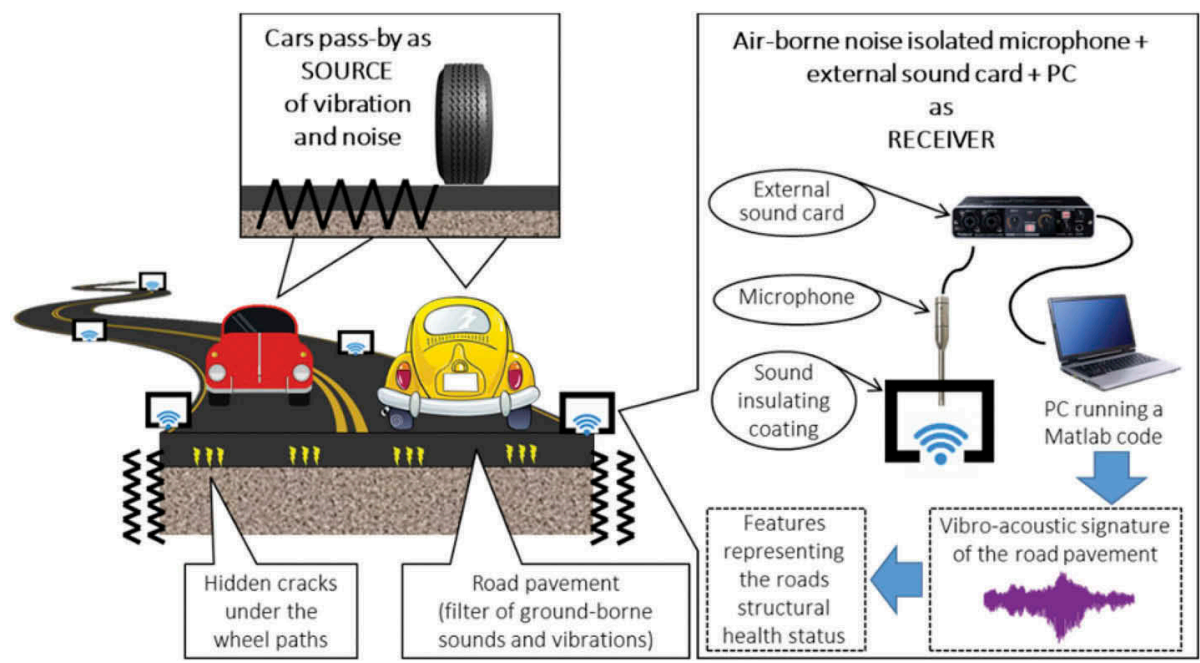

Figure 3. Schematic representation of the monitoring solution proposed in this study.

In this study the following devices were used as receiver (measurement chain): 1) Omnidirectional pre-polarized microphone "Audix TM1" (frequency response: $20-25 \mathrm{kHz} \pm 2 \mathrm{~dB}$, sensitivity: $6 \mathrm{mV} / \mathrm{Pa}$ at $1 \mathrm{kHz}$, dynamic range: $112 \mathrm{~dB}$ ), acoustically isolated using a plastic box filled with isolating material and modelling clay (used also to attach the box to the road). 2) External sound card "Roland quad-capture UA-55". 3) Recorder/Analyzer: ASUS ZenBook (model: UX433F, Intel ${ }^{\circledR}$ Core $^{\mathrm{TM}} \mathrm{i7} 78565 \mathrm{U}$, RAM: $16 \mathrm{~GB}$, 64bit x64) running MATLAB codes that allow recording acoustic signal with a sampling frequency of $192 \mathrm{KHz}$.

\section{URBAN ROAD TRIAL TEST}

In order to identify the cracked and uncracked areas to be investigated during the urban road trial test and the thickness of asphalt layer in these points, the Ground Penetrating Radar was used. About 300 meters long an urban road in Catania (South Italy) were covered in both directions, for a total of about 600 meters. 
Thanks to the K2_FW acquisition software, the thickness of asphalt layer was analysed along the entire path with a step of 1 meter and the presence of any underground services was identified. Only the areas in which the asphalt layer with uniform dense mix was thicker than $15 \mathrm{~cm}$ were taken into account (Figure 4).

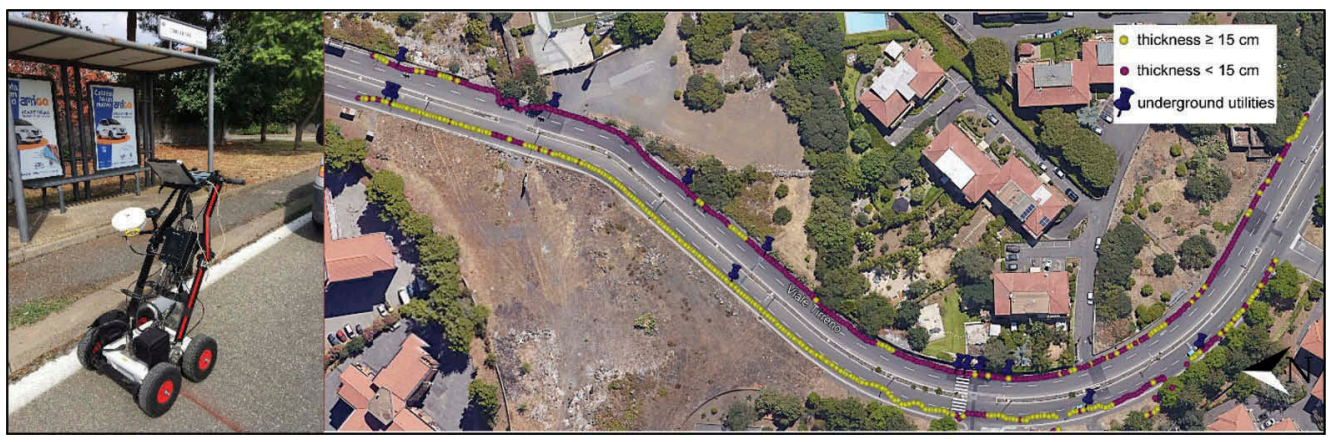

Figure 4. GPR investigation.

Through a visual inspection, among the areas having a similar thickness greater than $15 \mathrm{~cm}$, four sections were identified, two without surface cracking and two with cracks (Figure 5).

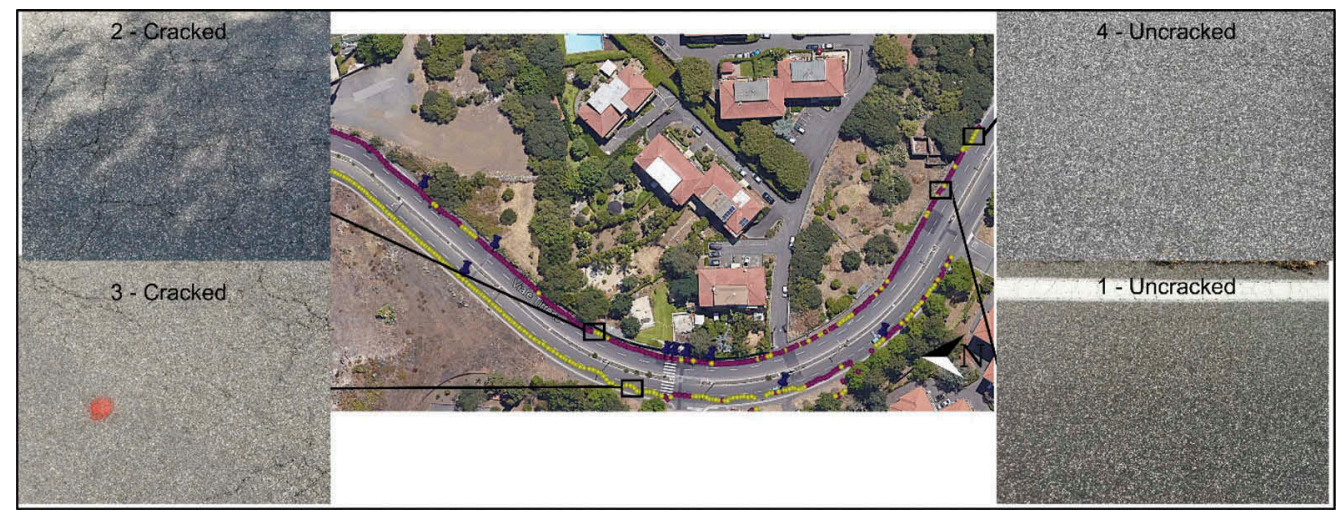

Figure 5. Selection of pavements in different conditions.

In each of the identified pavement areas, the test was carried out by loading the pavement with the FWD following the schema reported in the left part of Figure 6. In particular, once the vibro-acoustic sensor has been positioned on the pavement area under consideration, the tests were carried out as follows:

1. The first three load tests were carried out with the FWD plate in line with the microphone at a distance of 1,5 meters, the second moving the plate one meter back and the third one meter forward along the direction of travel;

2. The fourth loading test was carried out with the LWD positioned in line with the microphone at the same distance as the test with the FWD. 
During the tests carried out with the FWD, the mass was dropped 9 times from different heights in order to obtain different loads: i) the first of $56 \mathrm{kN}$ settling, ii) two of $40 \mathrm{kN}$, iii) two of $56 \mathrm{kN}$, iv) two of $84 \mathrm{kN}$ and v) two of $120 \mathrm{kN}$. For each load point, the FWD test was performed twice. The surface temperature was about the same during the overall test.

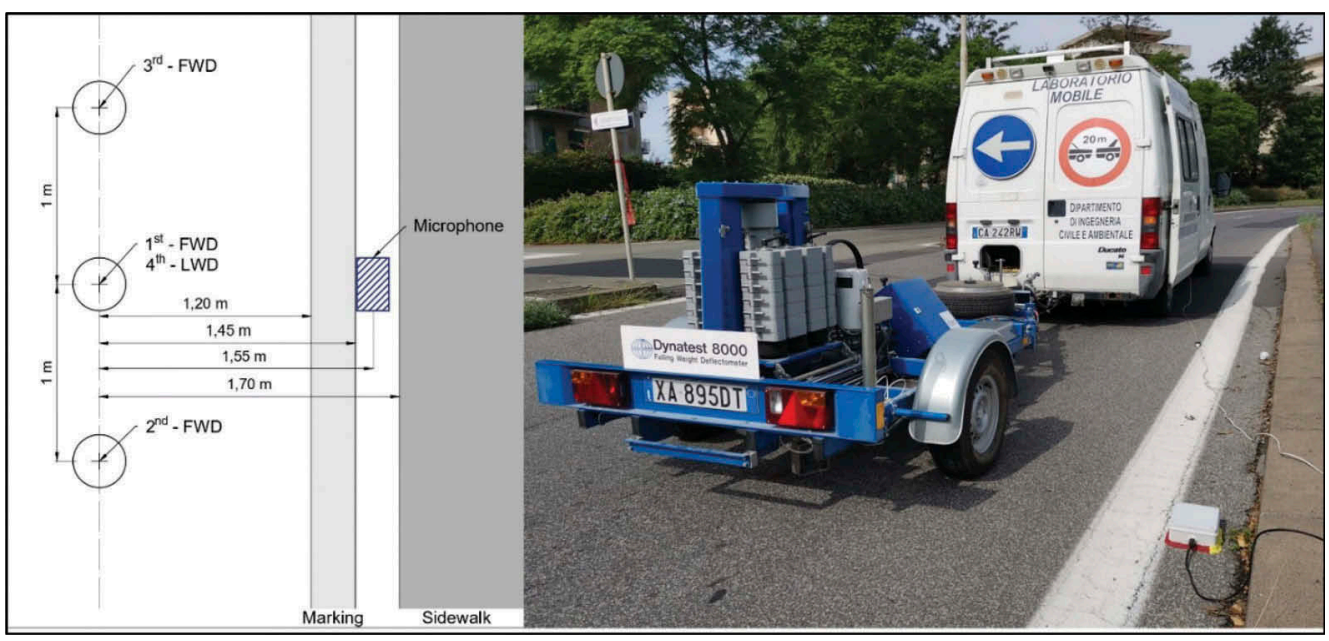

Figure 6. FWD and vibro-acoustic sensor schema of investigation.

\section{RESULTS}

During the experimental investigation, the FWD was applied as a source of vibration and noise at different loads. For the sake of simplicity, in the following, the load conditions were called FWD1 $(=40 \mathrm{kN})$, FWD2 $(=56 \mathrm{kN})$, FWD3 $(=84 \mathrm{kN})$, and FWD4 $(=120 \mathrm{kN})$. The following Figure 7 shows the deflection basins as the four load varies for un-cracked and cracked pavement referred to sections 1 and 2 . In the graphs, the dashed lines show the deflection basins in the cracked sections, while the solid lines refer to the uncracked sections. With 1.X all the FWD tests carried out in the first section (uncracked) are marked, while with 2.X those carried out in the second section (cracked). In both cases, $X=1$ and $X=2$ are the load tests carried out in the first point (in axis with the sensor), $X=3$ and $X=4$ are the tests carried out one meter before and $\mathrm{X}=5$ and $\mathrm{X}=6$ one meter later in the direction of travel.

Graphically it is already possible to highlight the significant difference in the behaviour of the two sections, a difference which is confirmed by the statistical diversity (t-test $0 \%$ ) of the averages of the under-plate deflection values $\left(D_{0}\right)$ and the $I_{200}$ index $\left(D_{200}-D_{0}\right)$ as measure of the bearing capacity of the surface layer, as reported in the Table 1. Similarly, in the different plate positions at the same test section the deflections were similar showing homogeneity of the pavement structure and conditions.

Figure 8 shows how an un-cracked section of the road pavement under investigation responded to the four loads mentioned above. As expected, the amplitude and the length of the road vibro-acoustic signatures undergoes an increase in time domain because of the increase of the applied load (Figure 8). Note that the FWD performed a couple of loads for each load condition, and for this reason the following figure shows a couple of signals (almost coincident; see "signal 1" and "signal 2" in figure).

Subsequently, the road vibro-acoustic signatures were transformed from the time to the frequency domain (Power Spectral Density, PSD, versus Frequency). Four examples of road's 


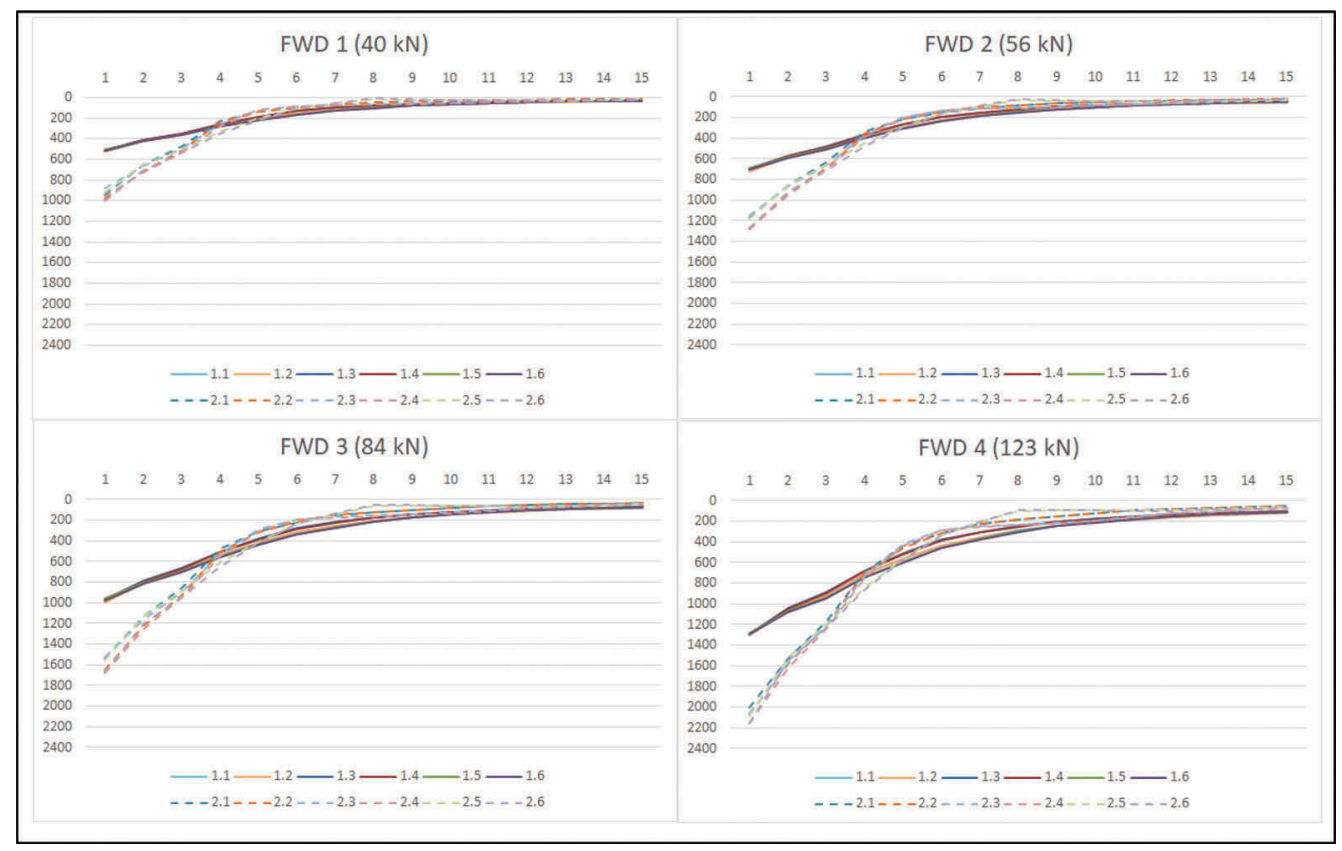

Figure 7. Deflection Basins corresponding to the 4 load levels.

Table 1. FWD data for section 1 and 2 .

\begin{tabular}{lccccccccc}
\hline Section & Stress & $\begin{array}{l}\text { Force } \\
{[\mathrm{kPa}]}\end{array}$ & $\begin{array}{l}\text { D0 }[\mathrm{m}] \\
{[\mathrm{kN}]}\end{array}$ & $\begin{array}{l}\text { IS200 }[\mathrm{m}] \\
10-6]\end{array}$ & Section & $\begin{array}{l}\text { Stress } \\
{[\mathrm{kPa}]}\end{array}$ & $\begin{array}{l}\text { Force } \\
{[\mathrm{kN}]}\end{array}$ & $\begin{array}{l}\text { D0 }[\mathrm{m} \\
10-6]\end{array}$ & $\begin{array}{l}\text { IS200 }[\mathrm{m} \\
10-6]\end{array}$ \\
\hline 1-uncracked & 545 & 39 & 516 & 69 & 2-cracked & 529 & 37 & 948 & 183 \\
& 790 & 56 & 704 & 90 & & 771 & 54 & 1222 & 229 \\
& 1181 & 83 & 976 & 126 & & 1155 & 82 & 1608 & 296 \\
& 1737 & 123 & 1298 & 170 & & 1696 & 120 & 2112 & 382 \\
\hline
\end{tabular}

vibro-acoustic signature in the frequency domain related to two different SHSs, i.e., uncracked and cracked, are shown in Figure 9.

Note that a 1/3 octave band spectrum was derived from each FWD load for each load condition, and that, as shown in figure, this representation of the road signature (i.e., in the frequency domain) is really useful to define the inappreciable differences among the signals.

From the signatures shown in Figure 9, three features were extracted (the first two ones from the time domain, and the third one from the frequency domain), based on:

1) $\Delta \mathrm{a}$ : difference between the absolute maximum $\mathrm{P}$ and the absolute minimum $\mathrm{N}$ of the signal amplitudes (arbitrary unit, a.u.).

2) $\Delta t$ : time delay of N-P (milliseconds).

3) fc: Spectral centroid of the spectrum (PSD vs. frequency) in the frequency range 16-2500 $\mathrm{Hz}$. This is measured in $\mathrm{Hz}$ and can be defined as the "center of mass" of a spectrum (Schubert and Wolfe, 2006)). The figures below show the trends of the three aforementioned features as a function of the FWD load.

Based on the features of Figures 10 and 11, it is possible to state that there is room to structure algorithms to use the proposed monitoring solution to detect the occurrence of damages 

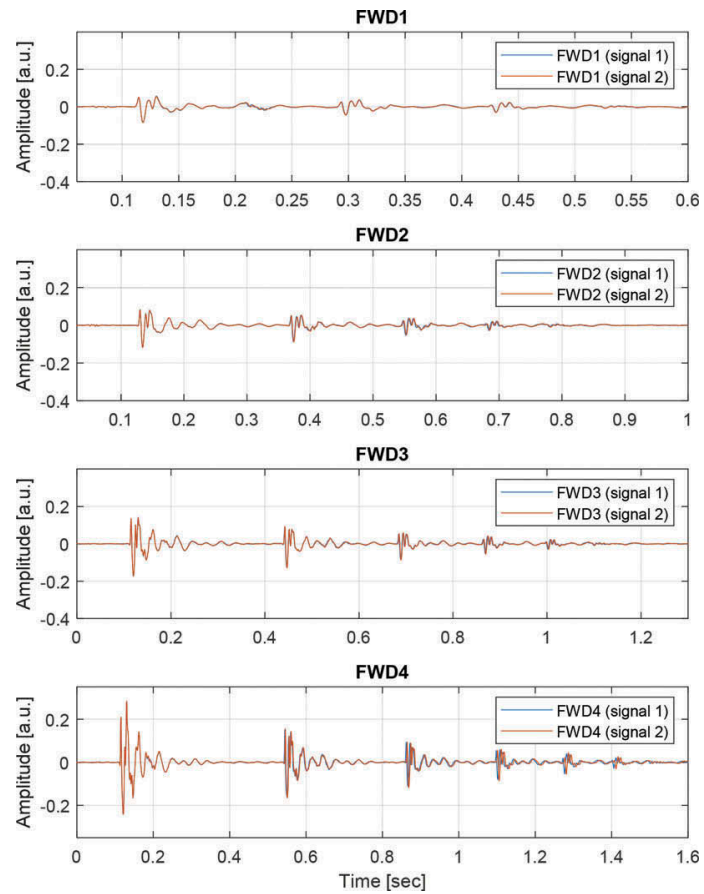

Figure 8. Example of vibro-acoustic responses of an un-cracked (left) and cracked (right) road pavements.

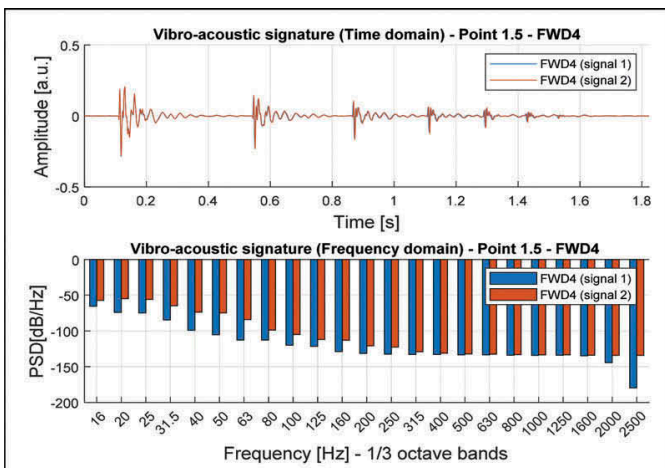

(a)

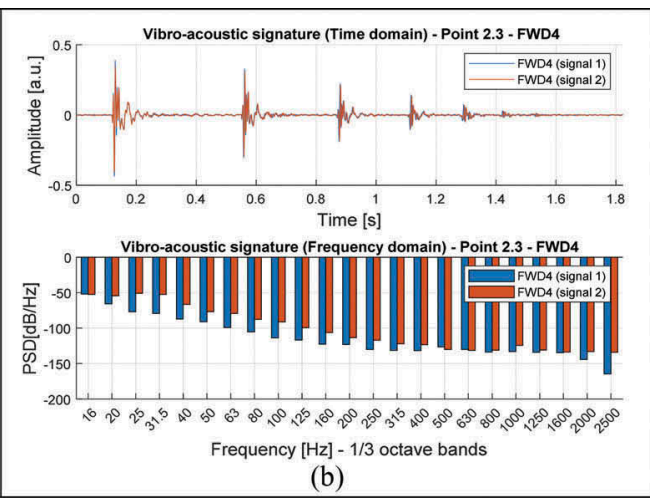

(b)

Figure 9. Examples of vibro-acoustic responses of the un-cracked (a) and cracked (b) road under investigation (points 1.5 and 2.3, respectively) and load condition FWD1 $(=120 \mathrm{kN})$.

in asphalt concrete pavements using meaningful features extracted from the time and the frequency domain of analysis. In more detail:

1) The first feature extracted, $\Delta \mathrm{a}$, shows that: 1.1) Some peaks of the road signature increase if the road SHS get worse (Figure 10); 1.2) This allows identifying different thresholds between un-cracked and cracked conditions as a function of the load applied (e.g., about 0.6 for $120 \mathrm{kN}$ ); 1.3) This trend exhibits (unlike the other features extracted) a clear proportionality with the load applied (i.e., assumes larger values if the load increases); 1.4) This 


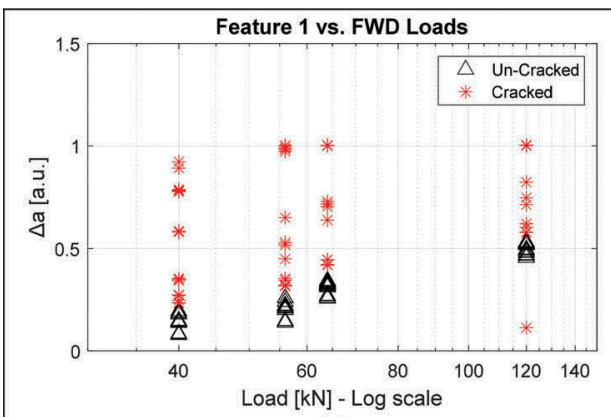

(a)

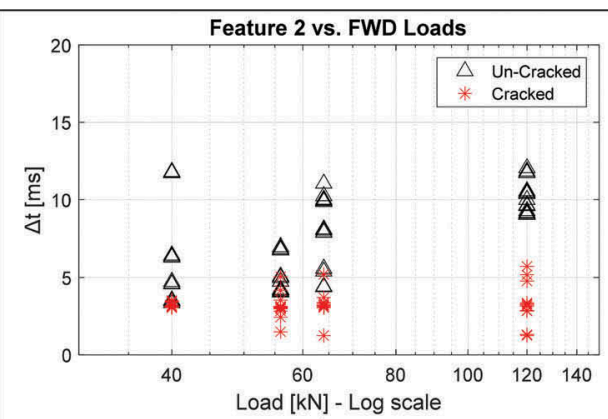

(b)

Figure 10. Features extracted in the time domain: (a) Feature 1 (i.e., Peak amplitude variation, $\Delta a$ ), and (b) Feature 2 (Peak delay, $\Delta \mathrm{t}$ ) as a function of the FWD load for two road pavement conditions (uncracked and cracked).

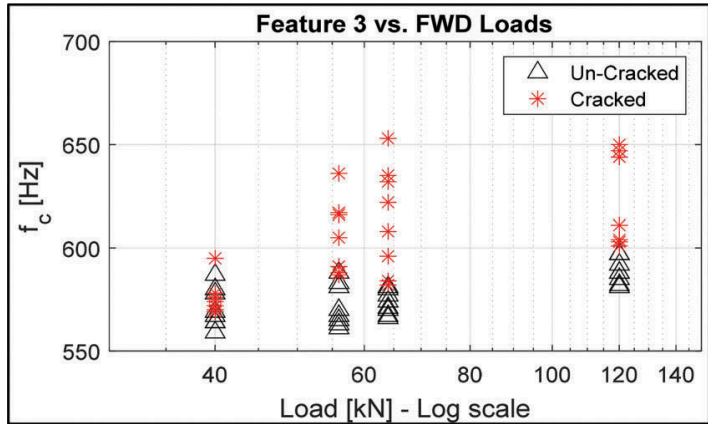

Figure 11. Feature extracted in the frequency domain: Feature 3 (i.e., Spectral centroid, fc) as a function of the FWD load, for 2 road pavement conditions.

shows (like the other features) that the dispersion of the values related to the cracked SHS is greater than that the one related to the un-cracked SHS.

2) The second feature extracted, $\Delta t$, shows how the road signatures get shorter (in time) when cracks are present on the road section (Figure 10), because of the reduction of the signals' queue.

3) The third feature extracted, fc, reports how cracks allow the road pavement to act as a mechanical filter that absorbs a part of the signals energy. This latter can be detected in the frequency domain (range of operation 16-2500 Hz) in terms of reduction of the power spectral density, PSD (for selected frequency components). In this case, the damages present into the cracked road section (point 2 above) seem to affect especially the frequencies below $2500 \mathrm{~Hz}$ (Figure 9), suggesting that crack lengths are probably higher than the thickness of the bituminous layer. Indeed, low frequencies correspond to high wavelengths and then to a quite high level of damage. This latter consideration could be supported by the fact that higher loads (e.g., greater than $56 \mathrm{kN}$ ) allow better discriminating the two SHSs taken into account in this study, because they cause higher stress into the lower layers. In contrast, when a load of $40 \mathrm{KN}$ is used, the Feature 3 appears to lose its ability to detect the SHS.

4) Better insights between un-cracked and cracked condition were obtained using the lowest and the highest loads. 


\section{CONCLUSIONS AND FUTURE WORKS}

Based on the first study, in Table 2 a SWOT analysis of the application of smart vibroacoustic sensors for the assessment of pavement residual life is proposed to drive the future development of the proposed and similar pavement monitoring systems.

Table 2. SWOT analysis for the application of smart vibro-acoustic sensors.

STRENGHTS (internal, positive factor) WEAKNESSES (internal, negative factor)

- Interesting NDT testing comparison results

- Reduced costs for a spread urban network pavement management

- Reduced number of operators

- Application of mathematical and analytical models

- Application of a patented NDT monitoring solution (system and method).
- Reliability of the results

- Variability of the results

- Need of calibration tests for the data acquisition

- Need of further development of a patented NDT monitoring solution (system and method) to obtain self-powered wireless sensing nodes

\section{OPPORTUNITIES (external, positive factor)}

- Development of new models for the interpretation of the results

- Approach to a field of engineering technique that is not "saturated "

- Possibility of agreements with public authorities or private companies that need an advanced know-how for development of its own procedures

\section{THREATS (external, negative factor)}

- Results distorted by unexpected and/or unforeseen conditions and on-board effects cannot be assessed

- Returning of untruthful data about the pavement condition

- Mistrust of the Public Administrations in the use of these devices for pavement management

Results, even if preliminary and based on a limited sample size, show that FWD can be effectively used to test and calibrate the new sensor proposed in the paper. It is possible to state that the proposed monitoring solution can be used to detect the occurrence of damages in asphalt concrete pavements using meaningful features extracted from the time (i.e., related to signals' amplitude) and the frequency (i.e., related to signals' Power Spectral Density, PSD) domain of analysis. Future works include: 1) The improvement of the proposed monitoring system (to obtain a self-powered wireless system) in order to address some of the objectives of the ongoing Italian project USR342 (cited above); 3) extension of the test sections including different pavement thickness and crack patterns; 3) The extension of the data analysis (e.g., using machine learning algorithms) by mean of further features manually or automatically extracted (Cafiso et al., 2020).

\section{ACKNOWLEDGEMENT}

This work has been financed by the PRIN 2017-2022 within the ongoing project USR342 and by the University of Catania within the project TIMUC (PIACERI).

\section{REFERENCES}

Al-Qadi, I., \& Lahouar, S., 2005. Part 4: Portland cement concrete pavement: measuring rebar cover depth in rigid pavements with ground-penetrating radar. Transportation Research Record: Journal of the Transportation Research Board, (1907), 80-85

ASTM D4748-10, 201. Standard Test Method for Determining the Thickness of Bound Pavement Layers Using Short-Pulse Radar, ASTM International, West Conshohocken, PA, 2015, doi: https://doi.org/ 10.1520/D4748-10R15 
Cafiso, S. and Di Graziano A., 2009. Monitoring and performance of AC pavements reinforced with steel mesh. International Journal of Pavement Research and Technology, Volume 2 Number 3, ISSN 1996 6814, Chinese Society of Pavement Engineering

Cafiso, S., Capace, B., D'agostino, C., Delfino, E., Di Graziano, A., 2018. Introduction of new systems for evaluation of ballast bearing capacity. Proceedings of the 10th International Conference on the Bearing Capacity of Roads, Railways and Airfields, pp. 1993-2001

Cafiso, S., Di Graziano, A., Goulias, D., D'Agostino C., 2019. Distress and profile data analysis for condition assessment in pavement management systems. International Journal of Pavement Research and Technology - Volume 12, Issue 5, September 2019, pp 527-536

Cafiso, S., Di Graziano, A., Fedele, R., Marchetta, V., Praticò, F. (2020) Sensor-based pavement diagnostic using acoustic signature for moduli estimation. International Journal of Pavement Research and Technology, 13 (6), pp. 573-580.

Ceylan, H., Bayrak, M.B., Gopalakrishnan, K., 2014. Neural networks applications in pavement engineering: A recent survey. International Journal of Pavement Research and Technology.

Ceylan, H., Gopalakrishnan, K., Kim, S., Taylor, P.C., Prokudin, M., Buss, A.F., 2013. Highway infrastructure health monitoring using micro-electromechanical sensors and systems (MEMS). Journal of Civil Engineering and Management.

Daniels, D.J., 2004. Ground Penetrating Radar, 2nd Edition. IET

Di Graziano A., Marchetta V., Cafiso S. 2020 Structural health monitoring of asphalt pavements using smart sensor networks: a comprehensive review. Journal of Traffic and Transportation Engineering (in press).

Fedele, R., 2020. Smart road infrastructures through vibro-acoustic signature analyses. Smart Innovation, Systems and Technologies 178, 1481-1490.

Fedele, R., Merenda, M., Praticò, F.G., Carotenuto, R., Della Corte, F.G., 2018. Energy harvesting for IoT road monitoring systems. Instrum. Mesure Metrologie 17, 605-623.

Fedele, R., Praticò, F.G., 2019. Monitoring infrastructure asset through its acoustic signature. Inter-Noise 2019 Madrid - 48th Int. Congress and Exhibition on Noise Control Eng.

Fernandes, F.M., Pais, J.C., 2017. Laboratory observation of cracks in road pavements with GPR. Construction and Building Materials.

Goulias, D.G., Cafiso, S., Di Graziano, A., Saremi, S.G., Currao, V., 2020. Condition Assessment of Bridge Decks through Ground-Penetrating Radar in Bridge Management Systems. Journal of Performance of Constructed Facilities, 34 (5) pp 1-13

Grace, R., 2015. Sensors to support the IoT for infrastructure monitoring: technology and applications for smart transport/smart buildings. MEPTEC-IoT.

Hasni, H., Alavi, A.H., Chatti, K., Lajnef, N., 2017. A self-powered surface sensing approach for detection of bottom-up cracking in asphalt concrete pavements: Theoreticallnumerical modeling. Construction and Building Materials 144, 728-746.

Iodice, M., Muggleton, J.M., Rustighi, E., 2020. The in-situ evaluation of surface-breaking cracks in asphalt using a wave decomposition method. Nondestructive Testing and Evaluation.

Iuele, T., Praticò, F.G., Vaiana, R., 2019. Fine aggregate properties vs asphalt mechanical behavior: An experimental investigation. Proceedings of the World Conference on Pavement and Asset Management, WCPAM 2017.

Lahouar, S., Al-Qadi, I., Loulizi, A., Clark, T., \& Lee, D., 2002. Approach to determining in situ dielectric constant of pavements: development and implementation at interstate 81 in Virginia. Transportation Research Record: Journal of the TRB, (1806), 81-87

Merenda, M., Carotenuto, R., Della Corte, F.G., Giammaria Pratico, F., Fedele, R., 2020. Self-powered wireless IoT nodes for emergency management. 20th IEEE Mediterranean Electrotechnical Conference, MELECON 2020 - Proceedings.

Mounier, D., Di Benedetto, H., Sauzéat, C., 2012. Determination of bituminous mixtures linear properties using ultrasonic wave propagation. Construction and Building Materials 36, 638-647.

Odoki J.B., Di Graziano A., Akena R., 2015. A multicriteria methodology for optimising road investments. Proceedings of the Institution of Civil Engineers ICE Transport, Volume 168 Issue TR1, pages 34-47

Ouma, Y.O., Hahn, M., 2017. Pothole detection on asphalt pavements from 2D-colour pothole images using fuzzy c-means clustering and morphological reconstruction. Automation in Construction 83, 196-211. https://doi.org/10.1016/j.autcon.2017.08.017

Praticò, F.G., 2001. Roads and Loudness: A More Comprehensive Approach. Road Materials and Pavement Design 2, 359-377.

Praticò, F.G., Fedele, R., Naumov, V., Sauer, T., 2020. Detection and monitoring of bottom-up cracks in road pavement using a machine-learning approach. Algorithms. Kraków, Pol 
Praticò, F.G., Fedele, R., Vizzari, D., 2017. Significance and reliability of absorption spectra of quiet pavements. Construction and Building Materials 140, 274-281.

Saarenketo, T., 2006. Electrical properties of road materials and subgrade soils and the use of ground penetrating radar in traffic infrastructure surveys ( $\mathrm{PhD}$ Thesis). University of Oulu

Schubert, E., Wolfe, J., 2006. Timbral brightness and spectral centroid. Acta Acustica United with Acustica 92, 820-825.

Yi, C.W., Chuang, Y.T., Nian, C.S., 2015. Toward Crowdsourcing-Based Road Pavement Monitoring by Mobile Sensing Technologies. IEEE Transactions on Intelligent Transportation Systems 16, 1905-1917.

Yu, Y., Zhao, X., Shi, Y., Ou, J., 2013. Design of a real-time overload monitoring system for bridges and roads based on structural response. Measurement: Journal of the International Measurement Confederation $46,345-352$.

Zhou, Z., Liu, W., Huang, Y., Wang, H., Jianping, H., Huang, M., Jinping, O., 2012. Optical fiber Bragg grating sensor assembly for $3 D$ strain monitoring and its case study in highway pavement. Mechanical Systems and Signal Processing 28, 36-49. 